11 Edgerton RE. Warrior Women: The Amazons of Dahomey and the Nature of War. Boulder, CO: Westwood Press, 2000; 45.

12 Zerjal T, Xue Y, Bertorelle G. The genetic legacy of the Mongols. Ann Hum Genet 2003; 72: 717-721.

13 Moore LT, McEvoy B, Cape E, Simms K, Bradley DG. A Ychromosome signature of hegemony in Gaelic Ireland. Am J Hum Genet 2006; 78: 334-338.

14 Betzig LL. Despotism and Differential Reproduction: A Darwinian View of History. New York, NY: Aldine Publishing Company, 1986.

15 Potts M, Short R. Ever Since Adam and Eve: The Evolution of Human Sexuality. Cambridge, UK: Cambridge University Press, 1999.

16 Yalom M. A History of the Wife. New York, NY: HarperCollins, $2001 ; 130$

17 Engels F. The Origin of the Family, Private Property and the State. New York, NY: International Publishers, 1964; 58.

18 Potts M, Campbell M. History of contraception. In: Sciarra J (ed.), Gynecology and Obstetrics (CD-ROM 2003 edition). Philadelphia, PA: Lippincott Williams and Wilkins, 2003; Vol. 6, Chapter 8
19 Lesthaeghe RJ. The Decline of Belgium Fertility. Princeton, NJ: Princeton University Press, 1977; 229.

20 Potts M. Two pills, two paths: a tale of gender bias. Endeavour 2003; 27: 127-130.

21 Potts M. The evolution of human sexual intercourse. A revisited philosophy: sex without reproduction. In: Benangiano G, Di Renzo GC, Cosmi EV (eds), The Evolution of the Meaning of Sexual Intercourse in the Human. Cortona, Italy: da Editirice Grafica l'Etruria, 1996

22 Du X. "Viagra deaths explained by new understanding of platelet clumping." Science Blog, University of Illinois at Chicago, January 2003. http://www.scienceblog.com/ community/older/2003/B/20036497.html [Accessed 14 January 2008].

23 Thornhill NW, Thornhill R. An evolutionary analysis of psychological pain following rape. Ethol Sociobiol 1990; 11: 155-193.

24 Chowdhury RH, Chowdhury Z. Achieving the Millennium Development Goal on Maternal Mortality; Gonoshathaya Kendra's Experience in Rural Bangladesh. Dhaka, Bangladesh: Gonoprokashani, 2007.

\title{
JOURNAL REVIEWS
}

Effects of continuous versus cyclical oral contraception: a randomized controlled trial. Legro RS, Pauli JG, Kunselman AR, Meadows JW, Kesner JS, Zaino RJ, et al. J Clin Endocrinol Metab 2008; 93: 420-429

There is continuing interest in the use of longcycle and continuous combined hormonal contraceptive regimens to improve premenstrual and menstrual ill-health. This paper is a welldesigned, randomised, double-blind trial involving a total of 62 healthy women taking either combined pills for 21 days plus 7 days of placebo over six cycles or continuous therapy for 168 days.

It was surprising to see that a $20 \mu \mathrm{g}$ ethinylestradiol and $1 \mathrm{mg}$ norethindrone acetate pill was chosen for this study. The authors explained that previously published work had reported more days of amenorrhoea and fewer days of spotting with such a preparation.

The subjects were studied for three menstrual cycles prior to enrolment. No hormonal contraception was taken during this time. They were then seen regularly during the 'active' phase of the study.

Just under $20 \%$ of women dropped out once taking the study medication with approximately half giving 'uncomfortable with the side effects' as their reason. The overall results are similar to previous published work with the total number of bleeding days similar between the two groups but significantly less moderate/heavy bleeding days occurring with the continuous therapy(mean 5.2 \pm 6.8 days) than cyclic dosing (mean $11 \pm 8.5$ days; $p=0.005$ ). Both groups had less bleeding over time; however unpredictable breakthrough bleeding was more common in the continuous regimen cohort ( $37.6 \pm 38.8$ vs $18.3 \pm 17.2$ days $)$.

These healthy, normal women taking continuous active pills had less associated menstrual pain and a favourable improvement in 'behaviour' during the premenstrual phase only. Perhaps a greater improvement would be expected if the study were to be repeated in those with premenstrual syndrome or dysmenorrhoea.

Women taking the continuous regimen had greater ovarian and endometrial suppression with one woman ovulating once. In the cyclic group rebound ovulation or suspected ovulation occurred in 11/60 cycles (18\%). These results suggest that continuous therapy should be more efficacious, however this needs to be borne out in practice.

Reviewed by Diana Mansour, FRCOG, FFSRH Consultant in Community Gynaecology, Contraception and Sexual Health Service, Newcastle upon Tyne Primary Care Trust, Newcastle upon Tyne, UK
Safety and efficacy of a single-rod etonogestrel implant (Implanon): results from 11 international clinical trials. Darney P, Patel A Rosen K, Shapiro LS, Kaunitz AM. Fertil Steril 2008; [Epub 17 April 2008]

Implanon ${ }^{\circledR}$ (etonogestrel implant) is currently the only contraceptive implant licensed in the UK and is familiar to most general practitioners and sexual and reproductive health care workers. This report, funded by Organon, provides an overview of the implant's efficacy, safety and bleeding patterns. It is a summary of the findings of 11 clinical trials undertaken in contraceptive clinics in the USA, Chile, Asia and Europe.

In the 942 patients enrolled, no pregnancies occurred with the implant in situ, but there were six reported pregnancies within 14 days of implant removal. This gave a cumulative Pearl index of 0.38

Of the adverse events reported, those that were most likely to be attributed to the implan included headache $(15.5 \%)$, weight gain $(12.0 \%)$, acne $(11.8 \%)$, breast pain $(10.2 \%)$, emotiona lability $(5.8 \%)$ and abdominal pain $(5.2 \%)$ Complications from implant insertion and removal were infrequent.

Due to the progestogen content of the implant, bleeding irregularities were expected and occurred commonly, with no particular pattern. Comparisons between the bleeding patterns of patients using Norplant ${ }^{\circledR}$ and Implanon were made, and showed Implanon to cause fewer bleeding and spotting days and more amenorrhoea. However, the statistical significance of these findings is limited by the small number of subjects involved in this part of the analysis

Interestingly, geographical differences were noted when considering reasons for discontinuation. In the North American and European populations, bleeding irregularities were considered much less acceptable, contributing to $14 \%$ of premature removals of the implant compared to only $4 \%$ in Southeast Asia, Chile and Russia. Side effects that were reported as reasons for discontinuation more frequently also showed regional differences with symptoms such as emotional lability, depression and weight gain more commonly cited by North American patients.

This report highlights the contraceptive effectiveness of Implanon and its genera tolerability; however, the geographical variation in results must be considered when counselling patients in the UK about common side effects and bleeding patterns in an attempt to minimise patient dissatisfaction. In addition, patients with a high body mass index were excluded from the studies, therefore these trials do not predict efficacy of Implanon in obese women.
Reviewed by Kate L Darlow, MBChB, DFSRH, Specialist Registrar, St John's Hospital,

Livingston, West Lothian, UK

Male hormonal contraception: a double-blind placebo-controlled study. Mommers E, Kersemaekers WM, Elliesen J, Kepers M, Apter D, Behre HM, et al. J Clin Endocrinol Metab 2008; [Epub 15 April 2008]

A hormonal contraceptive for men has been the subject of active research for over 50 years. During this time a large number of studies have been carried out that have clearly demonstrated a number of important points including, most crucially, that hormone-induced spermatogenic suppression can provide effective contraception for men, and that this is fully reversible. This can be achieved either with high doses of testosterone alone or, to reduce the dose, the testosterone is more usually given in combination with a progestogen, which is the case in this study.

Studies in this field have often been limited by small sample size and difficulties in comparing different treatments. It is therefore very encouraging to learn of this double-blind placebo-controlled design involving 354 men who received either a low- or high-release etonogestrel implant (the low-release implant being similar to Implanon ${ }^{\circledR}$ ) combined with one of three testosterone regimens using the longacting injectable formulation testosterone undecanoate or placebo.

Overall, this was a test of very effective regimens, and the placebo group was useful in highlighting the specific side effects. However, as in many previous studies there remain a small number of men who seem resistant to hormonal suppression, and therefore should this type of approach become widespread in use then a test of efficacy, as for example after a vasectomy, would need to be incorporated. Differences between groups were slight.

Disappointingly, however, both Organon and Schering have announced that they do not intend to pursue this line of research. Optimism is only maintained by the ongoing efforts of bodies such as the World Health Organization and the National Institutes of Health who continue to be active in this field.

Reviewed by Richard A Anderson, PhD, MRCOG Professor of Clinical Reproductive Science, Centre for Reproductive Biology, Queen's

Medical Research Institute, University of Edinburgh, Edinburgh, UK 